\title{
Inversion of uterus with sub mucus fundal fibroid with secondary infection and shock: a rare case report
}

\author{
K. S. Raja Kumari *, Radha S
}

Department of Obstetrics and Gynecology, Raichur Institute of Medical Sciences, Raichur, Karnataka, India

Received: 04 January 2015

Accepted: 13 February 2015

\section{*Correspondence:}

Dr. K. S. Raja Kumari,

E-mail: selmanandini@gmail.com

Copyright: (c) the author(s), publisher and licensee Medip Academy. This is an open-access article distributed under the terms of the Creative Commons Attribution Non-Commercial License, which permits unrestricted non-commercial use, distribution, and reproduction in any medium, provided the original work is properly cited.

\begin{abstract}
In inversion of uterus, fundus of uterus comes down in reverse direction, through the cervix, exposing endometrial surface. Diagnosis of inversion of uterus is often difficult. Cervix is drawn up and vaginal portion of cervix would not be palpable. The most common disorder in differential diagnosis is a prolapsed fibroid. Acute inversion commonly occurs in $3^{\text {rd }}$ stage of labor, and is an acute obstetric emergency. In our case, inversion of uterus occurred in non puerperal period, in menopausal woman, due to sub mucous fundal fibroid, with acute presentation. Patient was in shock with pyrexia, and successfully managed surgically, after treating infection and shock.
\end{abstract}

Keywords: Non-puerperal, Uterine inversion, Sub mucous fundal fibroid

\section{INTRODUCTION}

Chronic uterine inversion of the non-puerperal uterus is an uncommon event, reported approximately 100 times in the literature since $1940{ }^{1,2}$ Chronic non-puerperal uterine inversion is often associated with uterine pathology. Prolapsed fibroids tend to be the most common inciting factor with occasional reports of inversion associated with uterine neoplasm and endometrial polyps. ${ }^{3}$

Three contributing factors proposed for uterine inversion are: 1) sudden emptying of the uterus which was previously distended by a tumor 2) thinning of the uterine walls due to an intrauterine tumor, and 3) dilatation of the cervix. $^{3}$ The following is a case report of a woman who presented hospital with non-puerperal uterine inversion secondary to sub mucous fundal fibroid, associated with secondary infection, and shock in a postmenopausal woman.

\section{CASE REPORT}

A 52 years woman presented to causality of Raichur Institute of Medical Sciences hospital, with complaints of severe back ache and pain abdomen since 4 days and mass coming out from vagina since 2 days. She was referred from local hospital as prolapsed uterus. Married 34 years back, p1, had one male child of 30 years old, and her husband died 6 years back. She attained menopause 2 years before, but h/o mild irregular minimal bleeding even after para one menopause occasionally. But she had not consulted doctor. H/o white discharge with smell since 4 months. She was conscious and irritable, markedly pale, with a pulse rate of 100/minute, temp $101^{\circ} \mathrm{F}$, and BP $90 / 60 \mathrm{mmHg}$. At admission, was able to pass urine, but mass was causing inconvenience to attend to toilet, and patient was not able to walk properly because, the mass was in between thighs, and due to fever. Past medical, surgical, and family histories were not of clinical relevance. Abdomen was soft, mild tenderness in lower abdomen. 
Per speculum and bimanual examination findings: Huge mass about 14 X $13 \mathrm{~cm}$ presented outside vulva, attached to the inverted uterus at its lower pole i.e. fundus. It mimics as if the inverted uterus is attached like a stalk to this big mass. The cervix could not be seen. Due to secondary infection it was foul smelling, and uterus could not felt.

Provisional diagnosis of mass per vaginum was done with differential diagnosis of big cervical fibroid polyp, prolapsed uterus, and after sounding test diagnosed as inversion of uterus with sub mucus fundal fibroid with secondary infection. ${ }^{4,5}$

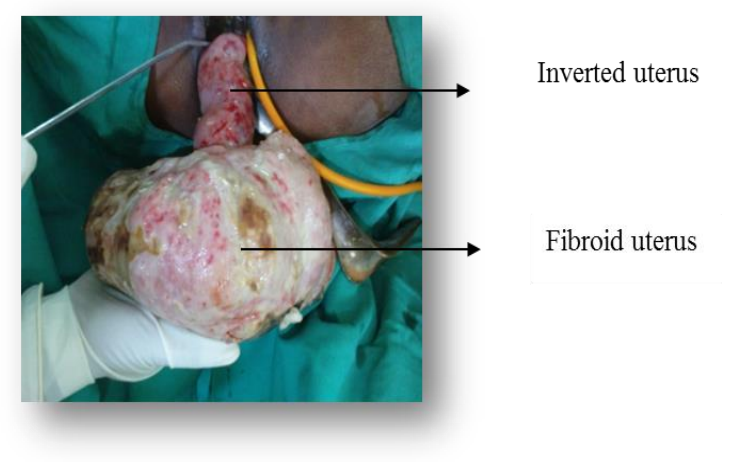

Figure 1: Fundal fibroid with uterine inversion.

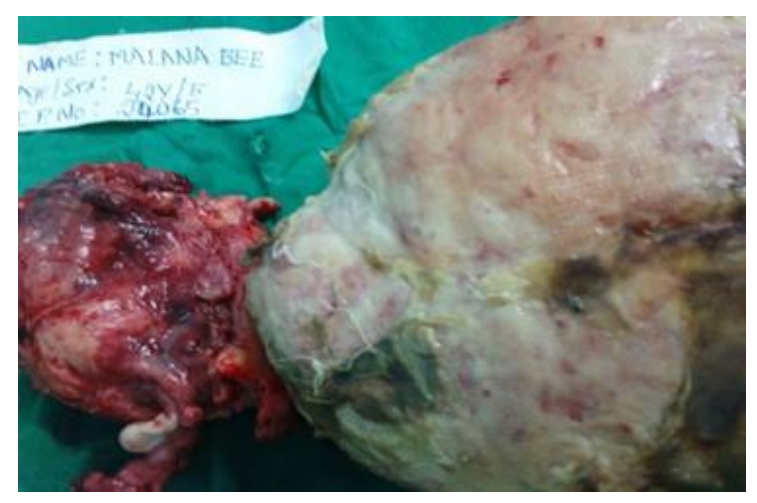

Figure 2: Hysterectomy Specimen with excised fibroid.

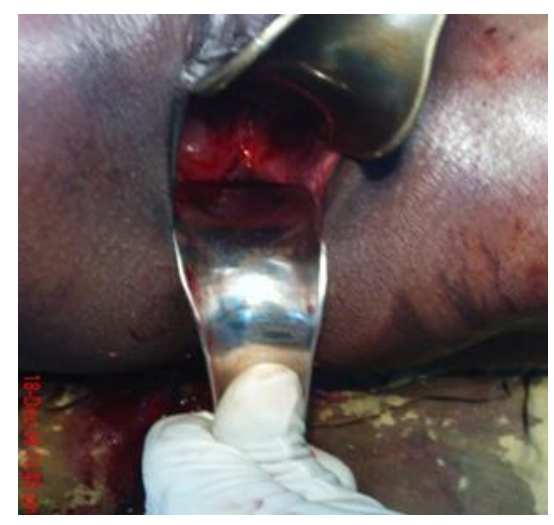

Figure 3: Vaginal Vault after surgery.

\section{Investigations}

HB\%: 5gram\%, leukocytosis, blood urea, serum creatinine, fever profile, and others investigations were normal.

Ultrasound examination: Abnormal uterine fundal contour with a homogeneous globular mass in vagina. Treatment: Treated with cefotaxime, Metrogyl and gentamycin for 5 days, 5 units of blood transfused. She was treated with daily dressing with antiseptic lotion and glycerine packing. She was given bed rest. After 7 days secondary infection was under control. Edema and congestion of the tumor reduced and she was submitted for surgery. In view of her age, was planned for vaginal hysterectomy. As the endometrial surface is exposed and bleeding was present from exposed endometrial surface, the big myoma attached to the inverted uterine fundus was excised first taking care that uterus was not perforated. After excision of myoma through vaginal route, as the tissue planes were not clearly visualized decided for abdominal hysterectomy. ${ }^{6}$ On opening the abdomen, both ovaries and tubes were found on either side of the constriction cup laterally. Cup's rim was cut on its posterior aspect, as the constricting ring was too tight and fundus was pushed up through cervix and with traction on round ligaments. Total abdominal hysterectomy, and B.S.O was done as usual and post op period is uneventful and discharged from hospital on $9^{\text {th }}$ post op day.

HPE: Leiomyoma of $13 \times 10 \mathrm{~cm}$, no evidence of malignancy. Uterus, cervix, and adnexa: unremarkable.

\section{Treatment options}

Restore the fundus to its correct position by section of constricting ring of the cervix, and then transected cervix should be repaired by suture.

Not desired to conserve uterus in multiparous women and vaginal or abdominal hysterectomy should be performed.

\section{Vaginal surgical approaches}

Vaginal surgical approaches are rarely performed. Transvaginally, the cervical constriction ring is incised posteriorly (Cascarides procedure) or anteriorly (Spinelli procedure), which should allow the uterus to be repositioned manually. The incision is then repaired. Incidental cystotomy is a hazard of the anterior approach.

\section{DISCUSSION}

Uterine inversion occurs when the uterine fundus collapses into the endometrial cavity, turning the uterus partially or completely inside out. Acute inversion of uterus in non-pregnant state is unusual. Acute inversion of uterus complicates generally $3^{\text {rd }}$ stage of labor and most commonly associated with mismanagement of $3^{\text {rd }}$ 
stage of labor. Chronic inversion consists of the late puerperal cases in which the initial stages of inversion occurred in the immediate postpartum period have been overlooked and those associated with extrusion of sub mucous fibroid of fundus. Diagnosis of chronic inversion is often difficult.

In our case, acute inversion occurred in post-menopausal woman with fundal fibroid ${ }^{7}$ and was associated with secondary infection. The leiomyoma might have exposed to vaginal environment resulting secondary infection with features of systemic infection in the patient. After treating her infection and improving her general condition only, we could manage her surgically.

Funding: No funding sources

Conflict of interest: None declared

Ethical approval: Not required

\section{REFERENCES}

1. Takano K, Ichikawa Y, Tsunoda H,Nishida M. Uterine inversion caused by uterine sarcoma: a case report. Jpn J Clin Oncol. 2001;31(1):39-42.

2. Simms-Stewart D, Frederick S, Fletcher H, Char G,Mitchell S. Postmenopausal uterine inversion treated by subtotal hysterectomy. J Obstet Gynaecol. 2008;28(1):116-7.
3. Rocconi R, Huh WK, Chiang S. Postmenopausal uterine inversion associated with endometrial polyps. Obstet Gynecol. 2003;102(3):521-3.

4. Eigbefoh JO, Okogbenin SA, Omorogbe F,Mabayoje PS. Chronic uterine inversion secondary to submucous fibroid: a case report. Niger J Clin Pract. 2009;12(1):106-7.

5. Chen YL, Chen CA, Cheng WF, Huang CY, Chang $\mathrm{CY}$, Lee CN, et al. Submucous myoma induces uterine inversion. Taiwan J Obstet Gynecol. 2006;45(2):159-61.

6. Haultain FWN. The treatment of chronic uterine inversion by abdominal hysterotomy, with a successful case. Br Med J. 1901:974-6.

7. Kopal S, Seckin NC,Turhan NO. Acute uterine inversion due to a growing submucous myoma in an elderly woman: case report. Eur J Obstet Gynecol Reprod Biol. 2001;99(1):118-20.

DOI: 10.5455/2320-1770.ijrcog20150439

Cite this article as: Kumari KSR, Radha S. Inversion of uterus with sub mucus fundal fibroid with secondary infection and shock: a rare case report. Int J Reprod Contracept Obstet Gynecol 2015;4:477-9. 